\title{
Kinetic, Thermodynamic and Isotherm Studies on the Removal of Methylene Blue Dye using Acid Activated Abutilon Indicum
}

\author{
A Kasthuri ${ }^{1}, \mathrm{~S} \mathrm{Arivoli}^{2} *, \mathrm{~V}$ Marimuthu ${ }^{2}$ and A Peter Pascal Regis ${ }^{3}$ \\ ${ }^{1}$ Department of Chemistry, Nehru Memorial College, Puthanampatti, Tamilnadu \\ ${ }^{2 *}$ Department of Chemistry, Thiru.Vi.Ka. Government Arts College Thiruvarur, Tamil Nadu, India \\ ${ }^{3}$ Department of Chemistry, St. Joseph College, Trichy, Tamilnadu, India
}

\begin{abstract}
The research of the present work was to investigate the removal of methylene blue dyes from aqueous solution by using Acid Activated Abutilon Indicum Leaves (AAAI). Generally, dyes are organic compounds used as colouring products in chemical, textile, paper, printing, leather, plastics and various food industries. The need for the treatment of dye contaminated waste water passed out from the industry. In this study, Abutilon Indicum Leaves were studied for its potential use as an adsorbent for removal of a cationic dye methylene blue. The various factors affecting adsorption, such as initial dye concentration, contact time, adsorbent dose and effect of temperature, were evaluated. The experimental data were fitted into the pseudosecond order kinetic model. The equilibrium of adsorption was modeled by using the Langmuir and Freundlich isotherm models. The objective of the present work suggests the AAAI may be utilized as a low cost adsorbent for methylene blue dye removal from aqueous solution.
\end{abstract}

Key words: Acid Activated Abutilon Indicum Leaves (AAAI); Methylene blue; Adsorption isotherm; Kinetics; Equilibrium models.

\section{Introduction}

Dyes are widely used, generally in the textiles, plastics, paper, leather, food industry to color products. In process of washing and finishing coloured products, waste water contaminated with dyes is generated. The contaminated waste waters are hazardous, which is a great threat to environment [1-3]. Dye contamination in wastewater causes problems in various ways: the presence of dyes in water, even in very low quantities, is highly visible and undesirable; color interferes with penetration of sunlight into waters; retards photosynthesis; inhibits the growth of aquatic biota and interferes with gas solubility in water bodies. These materials are the complicated organic compounds and they resist against light, washing and microbial invasions [4-7]. The need for the treatment of dye contaminated waste water arose from the environmental impact [8]. Activated minerals are one of the most popular adsorbents used for the removal of toxic substances from waste water. This could be related to their extended surface area [9]. The major use of Acid Activated Abutilon Indicum Leaves is in solution purification and for the removal of colour, odors and other unpleasant impurities from liquids, water supplies and vegetable and animal oils.

In recent years it has been increasingly used for the prevention of environmental pollution and antipollution laws have increased the sales of low-cost activated minerals for control the of air and water pollution. Various techniques like precipitation, ion exchange, chemical oxidation and adsorption have been used for the removal of toxic pollutant from, wastewater. Methylene blue (MB) is selected as a model compound for evaluating the potential of AAAI to remove dye from aqueous solution.

\subsection{Adsorption studies}

\section{Materials and Methods}

Methylene blue (MB) was employed for the adsorbate in the adsorption experiments. Adsorption from the liquid phase was carried out to verify the nature the porosity and the capacities of the samples. An aqueous solution with a concentration of $25-125 \mathrm{mg} / \mathrm{L}$ was prepared by mixing an appropriate amount of MB with distilled water adsorption experiments were conducted by placing $0.025 \mathrm{~g}$ of the AAAI samples and $50 \mathrm{ml}$ of the aqueous solution in a $250 \mathrm{ml}$ of glass-stoppered flask. The flask was then put in a constant-temperature shaker bath with a shaker speed of $150 \mathrm{rpm}$. The isothermal adsorption experiments were performed at $30 \pm 2^{\circ} \mathrm{C}$. 


\subsection{Preparation of adsorbent materials}

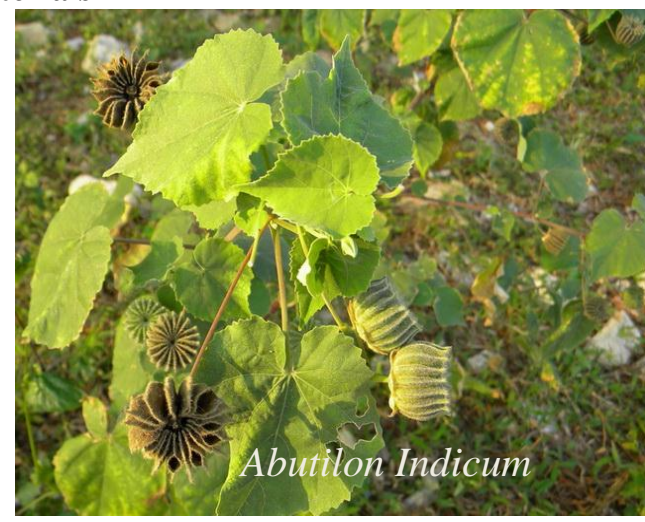

The Abutilon Indicum Leaves collected from agricultural area nearby Thiruvarur districts was Carbonized with concentrated Sulphuric Acid and washed with water and activated around $600^{\circ} \mathrm{C}$ in a muffle furnace for $5 \mathrm{hrs}$ the it was taken out, ground well to fine powder and stored in a vacuum desiccators.

\subsection{Preparation of adsorbate}

Methylene blue was chosen in this work because of its strong adsorption onto solids and it recognized usefulness in characterizing adsorptive material Methylene blue is employed to evaluate the adsorption characteristics of carbon. A known weight of $1000 \mathrm{mg}$ of MB was dissolved in about one litre of distilled water to get the stock solution.<smiles>CN(C)c1ccc2nc3ccc(N(C)C)cc3[s+]c2c1</smiles>

Structure of Methylene Blue

\subsection{Batch equilibrium method}

The adsorption experiments were carried out in a batch process at $30,40,50$ and $60^{\circ} \mathrm{C}$. A known weight of AAAI was added to $50 \mathrm{ml}$ of the dye solutions with an initial concentration of $25 \mathrm{mg} / \mathrm{L}$ to $125 \mathrm{mg} / \mathrm{L}$, which is prepared from $1000 \mathrm{mg} / \mathrm{L}$ of methylene blue stock solution. The contents were shaken thoroughly using a mechanical shaker with a speed of $150 \mathrm{rpm}$. The solution was then filtered at present time intervals and the residual dye concentration was measured.

\subsection{Characteristics of the adsorbent}

\section{Result and Discussions}

Acid Activated Abutilon Indicum Leaves is an effective adsorbent for the abatement of many pollutant compounds (organic, inorganic, and biological) of concern in water and wastewater treatment. Most of the solid adsorbents possess micro porous fine structure, high adsorption capacity, high surface area and high degree of surface, which consists of pores of different sizes and shapes. The wide usefulness of AAAI is a result of their specific surface area, high chemical and mechanical stability. The chemical nature and pore structure usually determines the sorption activity. The physico-chemical properties of the chosen adsorbent are listed in Table 1.

Table 1-Characteristics of the Adsorbent

\begin{tabular}{|c|c|}
\hline Properties & AAAI \\
\hline Particle size $(\mathrm{mm})$ & 0.010 \\
\hline Density $(\mathrm{g} / \mathrm{cc})$ & 0.1935 \\
\hline Moisture content $(\%)$ & 0.1784 \\
\hline Loss in ignition $(\%)$ & 0.010 \\
\hline $\mathrm{pH}$ of aqueous solution & 5.2 \\
\hline
\end{tabular}




\subsection{Effect of contact time and initial dye concentration}

The effect of contact time on the amount of dye adsorbed was investigated at $1000 \mathrm{mg} / \mathrm{L}$ concentration of the dye Fig. 1. It is observed that the percentage removal of dye increases rapidly with an increase in contact time initially, and thereafter, beyond a contact time of about $45 \mathrm{~min}$, no noticeable change in the percentage removal is observed the percentage removals after 45 min were $85 \%$. Therefore, the optimum contact time is considered to be $45 \mathrm{~min}$. this is also the equilibrium time of the batch adsorption experiments, since beyond a contact time of $45 \mathrm{~min}$, adsorption is not changed. The rapid removal of dye is observed at the beginning of the contact time due to the percentage of large number of binding sites available for adsorption. The experimental results of adsorptions at different concentrations ( 25 to $125 \mathrm{mg} / \mathrm{L}$ ) collected in Table 2 observed that percent adsorption decreased with increase in initial dye concentration, but the actual amount of dye adsorbed per unit mass of AAAI increased leads to increase in dye concentration. This means that the adsorption is highly dependent on initial concentration of dye. At lower concentration, the ratio of the initial number of dye molecules to the available surface area is low. Subsequently, the fractional adsorption becomes independent of initial concentration. However, at high concentration the available sites of adsorption become less and hence the percentage removal of dye is dependent upon initial concentration $[10,11]$.

\subsection{Effect of adsorbent dosage}

The adsorption of the methylene blue dye on AAAI was studied by varying the adsorbent dose (25-125 $\mathrm{mg} / 50 \mathrm{ml}$ ) for $50 \mathrm{mg} / \mathrm{L}$ of dye concentration. The percentage of adsorption increased with increases in the AAAI concentration, which is attributed to increased carbon surface area and the availability of more adsorption sites $[12,13]$. Hence, all studies were carried out with $0.025 \mathrm{~g}$ of adsorbent $/ 50 \mathrm{ml}$ of the varying adsorbate solutions.25, 50, 75, 100 and 125 . The Results obtained from this study are shown in Fig. 2. The amount of MB adsorbed per gram reduced with increase in the dosage of AAAI. This reveals that the direct and equilibrium capacities of MB are functions of the activated AAAI dosage.

\subsection{Effect of solution $\mathrm{pH}$}

The solution $\mathrm{pH}$ is one of the most important factors that control the adsorption of dye on the sorbent material. The adsorption capacity can be attributed to the chemical form of dye in the solution at specific $\mathrm{pH}$. In addition, due to different functional groups on the adsorbent surface, which become active sites for the dye binding at a specific $\mathrm{pH}$ the effect of adsorption can vary substantially. Therefore, an increase in $\mathrm{pH}$ may cause an increase or decrease in the adsorption, resulting different optimum $\mathrm{pH}$ values dependent on the type of adsorbent. To examine the effect of $\mathrm{pH}$ on the \% removal of $\mathrm{MB}$ dye, the solution $\mathrm{pH}$ were varied from 2.0 to 10.0 by adding acid and base to the stock solution This increases may be due to the presence of negative charge on the surface of the adsorbent AAAI that may be responds for the dye binding. However, as the $\mathrm{pH}$ is lowered, the hydrogen ions compete with dye for the adsorption sites in the adsorbent AAAI, the overall surface charge on the particles become positive and hinds the binding of positively charged dye. On other hand, decrease in the adsorption under $\mathrm{pH}>6.3$ may be due to occupation of the adsorption sites by $\mathrm{OH}^{-}$ions which retard the approach of such dye further toward the adsorbent AAAI surface. From the experimental results, the optimum $\mathrm{pH}$ range for the adsorption of the MB dye is 2.0 to 6.5 shown in Fig.3.

\subsection{Adsorption isotherms}

\subsubsection{Langmuir isotherm}

The theoretical Langmuir isotherm is used for adsorption of a solute from a liquid solution as monolayer adsorption on a surface containing a finite number of identical sites. Therefore, the Langmuir isotherm model was chosen for estimation of the maximum adsorption capacity corresponding to complete monolayer coverage on the adsorbent surface. The Langmuir non-linear equation is commonly expressed as follows:

$$
\mathrm{C}_{\mathrm{eq}} / \mathrm{Q}_{\mathrm{eq}}=1 / \mathrm{Q}_{\mathrm{m}} \mathrm{b}+\mathrm{C}_{\mathrm{eq}} / \mathrm{Q}_{\mathrm{m}} \ldots \ldots \ldots \ldots \ldots \ldots \ldots \text { (1) }
$$

Where $\mathrm{C}_{\mathrm{eq}}$ is the equilibrium concentration of adsorbate in the solution $(\mathrm{mg} / \mathrm{L}), \mathrm{Q}_{\mathrm{eq}}$ is the amount adsorbed at equilibrium $(\mathrm{mg} / \mathrm{g}), \mathrm{Q}_{\mathrm{m}}$ and $\mathrm{b}$ are Langmuir constants related to adsorption efficiency and energy of adsorption, respectively. The linear plots of Ceq/ $\mathrm{Q}_{\mathrm{eq}}$ vs. $\mathrm{C}_{\mathrm{eq}}$ suggest the applicability of the Langmuir isotherms. The values of $\mathrm{Q}_{\mathrm{m}}$ and $b$ were calculated from slope and intercepts of the plots are given in Table 3 . From the results, it is obvious that the value of adsorption efficiency $\mathrm{Q}_{\mathrm{m}}$ and adsorption energy $b$ of the AAAI increases on increasing the temperature. The values can conclude that the maximum adsorption corresponds to a saturated monolayer of adsorbate molecules on adsorbent surface with endothermic nature of adsorption [14, 15]. To confirm the favorability of the adsorption process, the separation factor $\left(\mathrm{R}_{\mathrm{L}}\right)$ was determined and given in Table 4.The values were established to be between 0 and 1 and confirm that the ongoing adsorption process is favorable [16]. 


\subsubsection{The Freundlich isotherm}

The Freundlich isotherm model is the earliest known equation describing the adsorption process. It is an empirical equation and can be used for non-ideal sorption that involves heterogeneous adsorption. The Freundlich equation was employed for the adsorption of methylene blue dye on the adsorbent. The Freundlich isotherm was represented by the following equation.

$$
\log \mathrm{Q}_{\mathrm{e}}=\log \mathrm{K}_{\mathrm{f}}+1 / n \log C_{\mathrm{e}}
$$

Where $\mathrm{Q}_{\mathrm{e}}$ is the amount of methylene blue dye adsorbed $(\mathrm{mg} / \mathrm{g}), C_{e}$ is the equilibrium concentration of dye in solution $(\mathrm{mg} / \mathrm{L})$, and $\mathrm{K}_{\mathrm{f}}$ and $\mathrm{n}$ are constants incorporating the factors affecting the adsorption capacity and intensity of adsorption, respectively. Linear plots of $\log \mathrm{Q}_{\mathrm{e}}$ versus $\log C_{\mathrm{e}}$ shows that the adsorption of methylene blue obeys the linear plots of $\log \mathrm{Q}_{\mathrm{e}}$ versus $\log C_{e}$ shows that the adsorption of methylene blue dye obeys the Freundlich adsorption isotherm. The values of $\mathrm{K}_{\mathrm{f}}$ and $n$ are given in Table 3 shows that the increase of negative charges on the adsorbent surface makes electrostatic force like Vanderwaal's between the AAAI surface and dye ion. The molecular weight and size either limit or increase the possibility of the adsorption of the dye onto adsorbent. However, the values clearly show the dominance in adsorption capacity.

The intensity of adsorption is an indication of the bond energies between dye and adsorbent, and the possibility of slight chemisorptions rather than physisorption $[17,18]$. However, the multilayer adsorption of methylene blue through the percolation process may be possible. The values of $n$ are less than one, indicating the physisorption is much more favorable.

\subsection{Effect of temperature}

To study the effect of temperature on the adsorption of dye adsorption by AAAI, the experiments were performed at temperatures of $30,40,50,60^{\circ} \mathrm{C}$. As it was observed that, the equilibrium adsorption capacity of MB onto AAAI was found to increase with increasing temperature, especially in higher equilibrium concentration, or lower adsorbent dose because of high driving force of adsorption. This fact indicates that the mobility of dye molecules increased with the temperature. The adsorbent shows the endothermic nature of adsorption. The adsorption capacity of the AAAI increased with increase of the temperature in the system from $30^{\circ}$ to $60^{\circ} \mathrm{C}$. Thermodynamic parameters such as change in free energy $\left(\Delta G^{\circ}\right)(\mathrm{kJ} / \mathrm{mol})$, enthalpy $\left(\Delta H^{\circ}\right)$ $(\mathrm{kJ} / \mathrm{mol})$ and entropy $\left(\Delta S^{\circ}\right)(\mathrm{J} / \mathrm{K} / \mathrm{mol})$ were determined using the following equations.

$$
\begin{aligned}
& \mathrm{K}_{0}=\mathrm{C}_{\text {solid }} / \mathrm{C}_{\text {liquid }} \\
& \Delta \mathrm{G}^{\circ}=-\mathrm{RT} \ln \mathrm{K}_{\mathrm{O}} \\
& \log \mathrm{K}_{0}=\Delta \mathrm{S}^{\circ} /(2.303 \mathrm{R})-\Delta \mathrm{H}^{\circ} /(2.303 \mathrm{RT})
\end{aligned}
$$

Where $K_{o}$ is the equilibrium constant, $C_{\text {solid }}$ is the solid phase concentration at equilibrium $(\mathrm{mg} / \mathrm{L})$, $\mathrm{C}_{\text {liquid }}$ is the liquid phase concentration at equilibrium $(\mathrm{mg} / \mathrm{L}), T$ is the temperature in Kelvin, and $R$ is the gas constant. The $\Delta \mathrm{H}^{\circ}$ and $\Delta \mathrm{S}^{\circ}$ values obtained from the slope and intercept of Van't Hoff plots are given in Table 5.The values of $\Delta \mathrm{H}^{\circ}$ is the range of 9 to $17 \mathrm{~kJ} / \mathrm{mol}$, indicate the physisorption. The results show that physisorption is much feasible for the adsorption of methylene blue. The positive values of $\Delta \mathrm{H}^{\circ}$ show the endothermic nature of adsorption which governs the possibility of physical adsorption [19, 20]. Because in the case of physical adsorption, while increasing the temperature of the system, the extent of dye adsorption increases, there is no possibility of chemisorption. The negative values of $\Delta G^{\circ}$ (Table 5) show that the adsorption is highly favorable and spontaneous. The positive values of $\Delta S^{\circ}$ (Table 5) show the increased disorder and randomness at the solid solution interface of methylene blue with AAAI adsorbent. The enhancement of adsorption capacity of the activated AAAI at higher temperatures was ascribed to the enlargement of pore size and activation of the adsorbent surface.

\subsection{Adsorption kinetics}

The study of adsorption dynamics describes the solute up take rate and evidently this rate controls the residence time of adsorbate uptake at the solid-solution interface .The kinetics of MB dye adsorption on the AAAI were analyzed using pseudo second-order[21] Elovich [22] and intra-particle diffusion[23] kinetic models. The conformity between experimental data and the model predicted values was expressed by the correlation co- efficient $(\gamma)$ and the values are close or equal to 1. A relatively high correlation coefficient $(\gamma)$ value indicates that the pseudo second-order model successfully describes the kinetics of MB dye adsorption.

\subsubsection{The pseudo second- order equation}

The pseudo second-order adsorption kinetic rate equation is expressed as

$$
\mathrm{dq}_{\mathrm{t}} / \mathrm{d}_{\mathrm{t}}=\mathrm{k}_{2}\left(\mathrm{q}_{\mathrm{e}}-\mathrm{q}_{\mathrm{t}}\right)^{2}
$$

Where: $\mathrm{k}_{2}$ is the rate constant of pseudo second- order adsorption $(\mathrm{g} \mathrm{mg} / \mathrm{min})$. For the boundary conditions $\mathrm{t}=0$ to $\mathrm{t}=\mathrm{t}$ and $\mathrm{q}_{\mathrm{t}}=0$ to $\mathrm{q}_{\mathrm{t}}=\mathrm{q}_{\mathrm{t}}$ the integrated form of Eq. (6) becomes: 


$$
1 /\left(\mathrm{q}_{\mathrm{e}}-\mathrm{q}_{\mathrm{t}}\right)=1 / \mathrm{q}_{\mathrm{e}}+\mathrm{K}_{2} \mathrm{t}
$$

This is the integrated rate law for a pseudo second-order reaction. Equation (7) can be rearranged to obtain Eq.(8), which has a linear form:

If the initial adsorption rate $(\mathrm{h})\left(\mathrm{mg} \mathrm{g}^{-1} \mathrm{~min}^{-1}\right)$ is :

$$
\mathrm{t} / \mathrm{q}_{\mathrm{t}}=\left(1 / \mathrm{k}_{2} \mathrm{q}_{\mathrm{e}}{ }^{2}\right)+\left(\left(1 / \mathrm{q}_{\mathrm{e}}\right) \mathrm{t}\right.
$$

$$
\mathrm{h}=\mathrm{k}_{2} \mathrm{q}_{\mathrm{e}}^{2}
$$

Equation (8) and (9) becomes,

$$
\mathrm{t} / \mathrm{q}_{\mathrm{t}}=1 / \mathrm{h}+1 / \mathrm{q}_{\mathrm{e}} \mathrm{t}
$$

The plot of $\left(t / \mathrm{q}_{\mathrm{t}}\right)$ and $\mathrm{t}$ of Eq. (10) should give a linear relationship from which $\mathrm{q}_{\mathrm{e}}$ and $\mathrm{k}_{2}$ can be determined from the slope and intercept of the plot, respectively. The pseudo-second order rate constants $\mathrm{K}_{2}$, the calculated $\mathrm{h}$ values, and the correlation coefficients $(\gamma)$ are summarized in Table (6).At all studied initial MB dye concentrations, the straight lines with extremely high correlation co-efficient $(>0.99)$ were obtained. From table 6 , the values of the rate constant $\mathrm{k}$ decrease with in increasing initial MB dye concentration for AAAI. This is shows that the sorption of MB dye on AAAI follows pseudo second order kinetic model [24, 25]

\subsubsection{The Elovich equation}

The Elovich model equation is generally expressed as

$$
\mathrm{dq}_{\mathrm{t}} / \mathrm{d}_{\mathrm{t}}=\alpha \exp \left(-\beta \mathrm{q}_{\mathrm{t}}\right) \quad \ldots \ldots . .(11)
$$

Where; $\alpha$ is the initial adsorption rate $\left(\mathrm{mg} \mathrm{g}^{-1} \mathrm{~min}^{-1}\right)$ and $\beta$ is the desorption constant $(\mathrm{g} / \mathrm{mg})$ during any one experiment. To simplify the Elovich equation [22] assumed $\alpha \beta \mathrm{t} \gg>\mathrm{t}$ and by applying boundary conditions $\mathrm{q}_{\mathrm{t}}=0$ at $\mathrm{t}=0$ and $\mathrm{q}_{\mathrm{t}}=\mathrm{q}_{\mathrm{t}}$ at $\mathrm{t}=\mathrm{t}$ Eq. (11) becomes:

$$
\mathrm{q}_{\mathrm{t}}=1 / \beta \ln (\alpha \beta)+1 / \beta \ln \mathrm{t}
$$

If MB dye adsorption fits with the Elovich model, a plot of $\mathrm{q}_{\mathrm{t}} \mathrm{vs}$. $\ln (\mathrm{t})$ should yield a linear relationship with a slope of $(1 / \beta)$ and an intercept of $(1 / \beta) \ln (\alpha \beta)$. The Elovich model parameters $\alpha$, $\beta$, and correlation coefficient $(\gamma)$ are summarized in table 6 . The experimental data such as the initial adsorption rate $(\alpha)$ adsorption constant $(\beta)$ and the correlation co-efficient $(\gamma)$ calculated from this model indicates that the initial adsorption $(\alpha)$ increases with temperature similar to that of initial adsorption rate (h) in pseudo-second-order kinetics models. This may be due to increase the pore or active site on the AAAI adsorbent.

\subsubsection{The intra particle diffusion model}

The intra-particle diffusion model used here refers to the theory proposed by Weber and Morris [23] based on the following equation for the rate constant:

$$
\mathrm{q}_{\mathrm{t}}=\mathrm{k}_{\mathrm{id}} \mathrm{t}^{(\mathrm{i} / 2)}+\mathrm{C} \text {. }
$$

Where $\mathrm{k}_{\mathrm{id}}$ is the intra-particle diffusion rate constant $(\mathrm{mg} / \mathrm{g} / \mathrm{min})$ and $\mathrm{C}$ is the constant. If the rate limiting step is intra-particle diffusion, then the graph drawn between $\left(\mathrm{q}_{\mathrm{t}}\right)(\mathrm{mg} / \mathrm{g})$ verses square root of the contact time $\left(\mathrm{t}^{1 / 2}\right)$ should yield a straight line passing through the origin. The slope of the will give the value of the intra-particle diffusion coefficient $\left(\mathrm{k}_{\mathrm{id}}\right)$ and correlation coefficient $(\gamma)$ indicate the fitness of this model. The value of $\mathrm{C}$ gives an idea about the thickness of the boundary layer. From these data the intercept value indicate that the line were not passing through origin, there are some other process affect the adsorption. But the correlation coefficient $(\gamma)$ value is very high, so that the intra-particle diffusion takes place along with other process that may affect the adsorption. The values are given in table 6 .

\subsubsection{Desorption studies:}

Desorption studies help to elucidate the nature of adsorption and recycling of the spent adsorbent and the dye. If the adsorbed dye can be desorbed using neutral $\mathrm{pH}$ water, then the attachment of the dye molecule of the adsorbent is by weak bonds. The effect of various reagents used for desorption studies. The results indicate that hydrochloric acid is a better reagent for desorption, because we could get more than $90 \%$ removal of adsorbed dyes. The reversibility of adsorbed dyes in mineral acid or base is in agreement with the $\mathrm{pH}$ dependent results obtained. The desorption of dye molecules by mineral acids and alkaline medium indicates that the dye was adsorbed onto the AAAI through physisorption as well as by chemisorptions mechanisms.

\section{Conclusion}

The present study has shown the effectiveness of using AAAI in the removal of methylene blue dye from aqueous solutions. Acid Activated Abutilon Indicum Leaves in different forms has a great role in modern life to clean environment. Abutilon Indicum Leaves can be good precursors for producing highly porous Acid Activated Abutilon Indicum Leaves by simple preparative methods. An adsorption test has been carried out for industrial pollutants (methylene blue) under different experimental conditions in batch mode. The adsorption of methylene blue was dependent on adsorbent surface characteristics, adsorbent dose, methylene blue 
concentration, time of contact and temperature. A study of the kinetic models on sorption showed that sorption fitted the pseudo second- order kinetics model. The $\Delta \mathrm{G}^{0}, \Delta \mathrm{H}^{0}$, and $\Delta \mathrm{S}^{0}$ reveals the favorability of adsorption. The thermodynamic parameters suggested that the adsorption on AAAI was a spontaneous and endothermic process.

\section{Acknowledgement}

The authors sincerely thank to the University Grants Commission, New Delhi for providing the fund from Major Research Project.

\section{Reference}

[1] Gulnaz O. A, Kaya F, Matyar F, Arikan, B et al., Sorption of basic dyes from aqueous solution by activated sludge. J.Hazardous Materials, 108, 2004, 183-188.

[2] Zhao M, Tang Z, Liu P . Removal of methylene blue from aqueous solution with silica nano-sheets derived from vermiculate. J.Hazardous Materials, 158, 2008, 43-51.

[3] Robinson T, Chandran B, Nigam P .From an artificial textile dye effluent by two agricultural waste residues, corn corb and barley husk. Environ. Int. 28, 2002, 29-33.

[4] Wang S, Boyjoo Y, Choueib A . Comparative study of dye removal using fly ash treated by different methods. Chemosphere 60, 2005, 1401-1407.

[5] O"zer A, Dursun G . Removal of methylene blue from aqueous solution by dehydrated wheat bran carbon. J. Hazard. Materials.146, 2007, 262-269.

[6] Strivastava K.A, Gupta S. K, Iyer, M.V.S . Colour Removal from Paper Mill Waste. J. of Inst. Public Health Eng. India, part 2/3, 1984, 59-64.

[7] Nevskaia D, Saantianes A, Munoz V, Guerrero-Ruiz A et al.,. Interaction of aqueous solutions of phenol with commercial activated carbons: an adsorption and kinetic study. Carbon 37, 1999, 1065-1074.

[8] Froix M.F, Nelson R, The interaction of water with cellulose from nuclear magnetic resonance relaxation times. Macromolecules 8, 1975, 726-730.

[9] Barton S.S, The adsorption of methylene blue by active carbon. Carbon 25, 1987, 343-350.

[10] Al - Ghouti M.A, Khrasheh M.A.M Allen S.J, Ahmed M.N et al., The Removal of Dyes from Textile Wastewater: A Study of the Physical Characteristic and Adsorption Mechanisms of Diatomaceous Earth, Journal of Environmental Management, 69, $2003,229-238$.

[11] Bhattacharyya K.G, Sharma A, Kinetics and Thermodynamics of Methylene Blue Adsorption on Neem Leaf Powder, Dyes and Pigments, 65, 2005, 51-59.

[12] Namasivayam C, Muniasamy N, Gayathri K ,Rani M, Renganathan K et al., Removal of Dyes from Aqueous Solution by Cellulosic Waste Orange Peel, Biores Technol, 57, 1996, 37.

[13] Namasivayam C, Yamuna R. T, Adsorption of Direct Red by Biogas Residual Slurry, Environ Pollut, 89, 1995, p. 1.

[14] Krishna D.G, Bhattacharyya G. Adsorption of Methylene Blue on Kaolinite, Appl. Clay Sci. 20,2002, 295.

[15] Arivoli S, Hema M, Comparative Study on the Adsorption Kinetics and Thermodynamics of Dyes onto Acid Activated Low Cost Carbon”, Intern J Phys Sci., 2007, 10-17.

[16] Arivoli S, Venkatraman B. R, Rajachandrasekar T, Hema. M et al., Adsorption of Ferrous Ion from Aqueous Solution by Low Cost Activated Carbon Obtained from Natural Plant Material, Res J Chem, 17, 2007, 70-78.

[17] Freundlich H "Adsorption in Solutions", Phys. Chemie, 57, 1906, 384.

[18] Arivoli S, Viji Jain M, Rajachandrasekar T, Cobalt Adsorption on a Low Cost Carbon-Kinetic, Equilibrium and Mechanistic Studies, Mat. Sci. Res. India, 3, 2006, 241-250.

[19] Arivoli S, Kalpana K, Sudha, R, Rajachandrasekar T, Comparative Study on the Adsorption Kinetics and Thermodynamics of Metal Ions onto Acid Activated Low Cost Carbon, E J Chem, 4, 2007, 238-254.

[20] Renmin Gong, Yingzhi Sun, Jian Chen, Huijun Liu, and Chao Yang, Effect of Chemical Modification on Dye Adsorption Capacity of Peanut Hull, Dyes and Pigments, 67, 2005, 179.

[21] Vadivelan V, Vasanthkumar K. J, Equilibrium, kinetics, mechanism and design for the sorption of methylene blue onto rise husk. J. Colloid Interface Sci., 286, 2005, 91.

[22] [24] Chien S H, Clayton W R, Application of Elovich Equation to the kinetics of Phosphate release and sorption on soil, Soil Sci. Sco, Am. J. 44, 1980, $265-268$.

[23] Weber W J, Morris J C, “Kinetics of adsorption on Carbon from solution”. J, Sanitary Eng, Div. 90, 1964, 79.

[24] HASSLER W, Purification with activated carbon, chemical publishing Co, Inc., New York, 1974.

[25] Arivoli S, Kinetic and Thermodynamic Studies on the Adsorption of Some Metal Ions and Dyes onto Low Cost Activated Carbons, Ph D. Thesis, Gandhi gram Rural University, Gandhi gram, 2007.

Table: 2 Equilibrium Parameters for Adsorption of MB Dye onto AAAI

\begin{tabular}{|c|c|c|c|c|c|c|c|c|c|c|c|c|}
\hline \multirow[b]{2}{*}{$\mathbf{M}_{0}$} & \multicolumn{4}{|c|}{$\mathrm{Ce}(\mathrm{Mg} / \mathrm{L})$} & \multicolumn{4}{|c|}{ Qe $(\mathrm{Mg} / \mathrm{g})$} & \multicolumn{4}{|c|}{ Removal (\%) } \\
\hline & $\begin{array}{c}30^{\circ} \\
\mathrm{C}\end{array}$ & $\begin{array}{c}40^{\circ} \\
\mathrm{C}\end{array}$ & $\begin{array}{c}\mathbf{5 0}^{\circ} \\
\mathbf{C}\end{array}$ & $\begin{array}{c}60^{\circ} \\
\mathrm{C}\end{array}$ & $\begin{array}{c}30^{\circ} \\
\mathrm{C}\end{array}$ & $40^{\circ} \mathrm{C}$ & $50^{\circ} \mathrm{C}$ & $60^{\circ} \mathrm{C}$ & $\begin{array}{c}30^{\circ} \\
\mathrm{C}\end{array}$ & $\begin{array}{c}40^{\circ} \\
\mathrm{C}\end{array}$ & $\begin{array}{c}\mathbf{5 0}^{\circ} \\
\mathbf{C}\end{array}$ & $\begin{array}{c}60^{\circ} \\
\mathrm{C}\end{array}$ \\
\hline 25 & 1.45 & 1.26 & 1.03 & 1.09 & 47.09 & 47.47 & 47.92 & 47.81 & 94.18 & 94.94 & 95.84 & 95.62 \\
\hline 50 & 5.28 & 4.84 & 3.21 & 3.00 & 89.43 & 90.30 & 93.56 & 93.98 & 89.43 & 90.30 & 93.56 & 93.98 \\
\hline 75 & 11.63 & 10.35 & 10.00 & 9.07 & 126.7 & 129.28 & 129.98 & 131.84 & 84.48 & 86.18 & 86.65 & 87.89 \\
\hline 100 & 25.76 & 23.26 & 10.00 & 19.62 & 148.4 & 153.46 & 179.98 & 160.75 & 74.23 & 76.73 & 89.99 & 80.37 \\
\hline 125 & 41.87 & 37.76 & 21.76 & 30.76 & 166.2 & 174.46 & 206.47 & 188.47 & 66.50 & 69.78 & 82.58 & 75.38 \\
\hline
\end{tabular}


Kinetic, Thermodynamic and Isotherm Studies on the Removal of Methylene Blue Dye using Acid

Table: 3 Langmuir and Freundlich Isotherm Parameter for Adsorption of MB onto AAAI

\begin{tabular}{|c|c|c|c|c|}
\hline \multirow{2}{*}{ TEMP. } & \multicolumn{2}{|c|}{ LANGUMUIR PARAMETERS } & \multicolumn{2}{c|}{ FRUENDLICH PARAMETERS } \\
\cline { 2 - 5 } & $\mathbf{Q}_{\mathbf{m}} \mathbf{C}$ & $\mathbf{b}$ & $\mathbf{K}_{\mathbf{f}}$ & $\mathbf{n}$ \\
\hline $\mathbf{3 0}^{\circ}$ & 183.88 & 0.19 & 5.20 & 2.66 \\
\hline $\mathbf{4 0}^{\circ}$ & 193.91 & 0.20 & 5.31 & 2.60 \\
\hline $\mathbf{5 0}^{\circ}$ & 249.85 & 0.18 & 5.45 & 2.08 \\
\hline $\mathbf{6 0}^{\circ}$ & 207.88 & 0.23 & 5.58 & 2.56 \\
\hline
\end{tabular}

Table: 4 Dimensionless Separation Factor $\left(R_{L}\right)$ for Adsorption of MB onto AAAI

\begin{tabular}{|c|c|c|c|c|}
\hline \multirow{2}{*}{$\left(\mathbf{C}_{\mathbf{i}}\right)$} & \multicolumn{4}{|c|}{ TEMPERATURE $^{\circ} \mathbf{C}$} \\
\cline { 2 - 5 } & $\mathbf{3 0}^{\circ} \mathbf{C}$ & $\mathbf{4 0}^{\circ} \mathbf{C}$ & $\mathbf{5 0}^{\circ} \mathbf{C}$ & $\mathbf{6 0}^{\circ} \mathbf{C}$ \\
\hline $\mathbf{2 5}$ & 0.17 & 0.16 & 0.17 & 0.14 \\
\hline $\mathbf{5 0}$ & 0.09 & 0.09 & 0.09 & 0.07 \\
\hline $\mathbf{7 5}$ & 0.06 & 0.06 & 0.06 & 0.05 \\
\hline $\mathbf{1 0 0}$ & 0.04 & 0.04 & 0.05 & 0.04 \\
\hline $\mathbf{1 2 5}$ & 0.03 & 0.03 & 0.04 & 0.03 \\
\hline
\end{tabular}

Table: 5 Thermodynamic Parameter for Adsorption of MB onto AAAI

\begin{tabular}{|c|c|c|c|c|c|c|}
\hline \multirow{2}{*}{$\mathrm{C}_{0}$} & \multicolumn{4}{|c|}{$\Delta \mathbf{G}^{\circ}$} & \multirow{2}{*}{$\Delta \mathbf{H}^{\circ}$} & \multirow{2}{*}{$\Delta \mathbf{S}^{\circ}$} \\
\hline & $30^{\circ} \mathrm{C}$ & $40^{\circ} \mathrm{C}$ & $50^{\circ} \mathrm{C}$ & $60^{\circ} \mathrm{C}$ & & \\
\hline 25 & -7015.00 & -7630.64 & -8429.44 & -8540.5 & 9.38 & 54.37 \\
\hline 50 & -5380.48 & -5808.03 & -7188.37 & -7608.42 & 19.13 & 80.61 \\
\hline 75 & -4269.3 & -4764.78 & -5024.06 & -5489.47 & 7.59 & 39.24 \\
\hline 100 & -2665.32 & -3105.22 & -5898.05 & -3903.43 & 17.73 & 68.00 \\
\hline 125 & -1727.31 & -2178.32 & -4180.44 & -3099.26 & 17.24 & 63.02 \\
\hline
\end{tabular}

Table: 6 The Kinetic Parameters for Adsorption of MB onto AAAI

\begin{tabular}{|c|c|c|c|c|c|c|c|c|c|c|c|}
\hline \multirow[t]{2}{*}{$\mathrm{C}_{0}$} & \multirow[t]{2}{*}{ Temp ${ }^{\circ} \mathrm{C}$} & \multicolumn{4}{|c|}{ PSEUDO SECOND ORDER } & \multicolumn{3}{|c|}{ ELOVICH MODEL } & \multicolumn{3}{|c|}{$\begin{array}{l}\text { INTRAPARTICLE } \\
\text { DIFFUSION }\end{array}$} \\
\hline & & $q_{e}$ & $k_{2}$ & $\gamma$ & h & $\alpha$ & $\beta$ & $\gamma$ & $\mathbf{K}_{\text {id }}$ & $\gamma$ & C \\
\hline \multirow{4}{*}{25} & 30 & 51.96 & $29 \times 10^{-3}$ & 0.996 & 7.91 & 64.98 & 0.13 & 0.9921 & 1.65 & 0.9912 & 0.18 \\
\hline & 40 & 50.27 & $46 \times 10^{-3}$ & 0.993 & 11.83 & 1656.7 & 0.21 & 0.9924 & 1.78 & 0.9914 & 0.10 \\
\hline & 50 & 50.93 & $44 \times 10^{-3}$ & 0.991 & 11.53 & 1383.8 & 0.20 & 0.9930 & 1.78 & 0.9915 & 0.10 \\
\hline & 60 & 50.43 & $46 \times 10^{-3}$ & 0.9960 & 11.86 & 4751.2 & 0.23 & 0.9915 & 1.80 & 0.9917 & 0.09 \\
\hline \multirow{4}{*}{50} & 30 & 97.30 & $17 \times 10^{-3}$ & 0.994 & 16.85 & 260.38 & 0.07 & 0.9940 & 1.67 & 0.9918 & 0.15 \\
\hline & 40 & 97.13 & $23 \times 10^{-3}$ & 0.9955 & 22.21 & 1107.8 & 0.09 & 0.9923 & 1.73 & 0.9919 & 0.12 \\
\hline & 50 & 100.1 & $20 \times 10^{-3}$ & 0.9952 & 20.47 & 1697.7 & 0.09 & 0.9928 & 1.75 & 0.9921 & 0.11 \\
\hline & 60 & 99.30 & $22 \times 10^{-3}$ & 0.9953 & 22.30 & 3591.8 & 0.10 & 0.9927 & 1.77 & 0.9923 & 0.10 \\
\hline \multirow{4}{*}{75} & 30 & 135.8 & $14 \times 10^{-3}$ & 0.9942 & 25.96 & 1134.4 & 0.06 & 0.9926 & 1.69 & 0.9925 & 0.12 \\
\hline & 40 & 139.1 & $13 \times 10^{-3}$ & 0.9961 & 25.49 & 831.93 & 0.06 & 0.9933 & 1.68 & 0.9928 & 0.13 \\
\hline & 50 & 138.3 & $15 \times 10^{-3}$ & 0.9956 & 28.84 & 2021.4 & 0.07 & 0.9935 & 1.72 & 0.9938 & 0.11 \\
\hline & 60 & 140.6 & $14 \times 10^{-3}$ & 0.9974 & 28.64 & 1588.2 & 0.06 & 0.9936 & 1.71 & 0.9945 & 0.12 \\
\hline \multirow{4}{*}{100} & 30 & 160.0 & $11 \times 10^{-3}$ & 0.9941 & 29.07 & 874.81 & 0.05 & 0.9939 & 1.62 & 0.9961 & 0.13 \\
\hline & 40 & 166.4 & $10 \times 10^{-3}$ & 0.9944 & 29.11 & 683.98 & 0.05 & 0.9940 & 1.62 & 0.9967 & 0.14 \\
\hline & 50 & 168.1 & $11 \times 10^{-3}$ & 0.9922 & 31.21 & 951.56 & 0.05 & 0.9941 & 1.64 & 0.9969 & 0.13 \\
\hline & 60 & 172.9 & $10 \times 10^{-3}$ & 0.9932 & 31.38 & 1046.2 & 0.05 & 0.9943 & 1.65 & 0.9968 & 0.13 \\
\hline \multirow{4}{*}{125} & 30 & 175.2 & $12 \times 10^{-3}$ & 0.9973 & 39.39 & 5003.1 & 0.06 & 0.9937 & 1.62 & 0.9977 & 0.10 \\
\hline & 40 & 188.1 & $9 \times 10^{-4}$ & 0.9935 & 33.28 & 914.40 & 0.04 & 0.9928 & 1.58 & 0.9975 & 0.13 \\
\hline & 50 & 194.2 & $9 \times 10^{-4}$ & 0.9936 & 33.94 & 867.17 & 0.04 & 0.9920 & 1.59 & 0.9974 & 0.14 \\
\hline & 60 & 203.8 & $8 \times 10^{-4}$ & 0.9939 & 34.47 & 922.38 & 0.04 & 0.9919 & 1.62 & 0.9978 & 0.14 \\
\hline
\end{tabular}




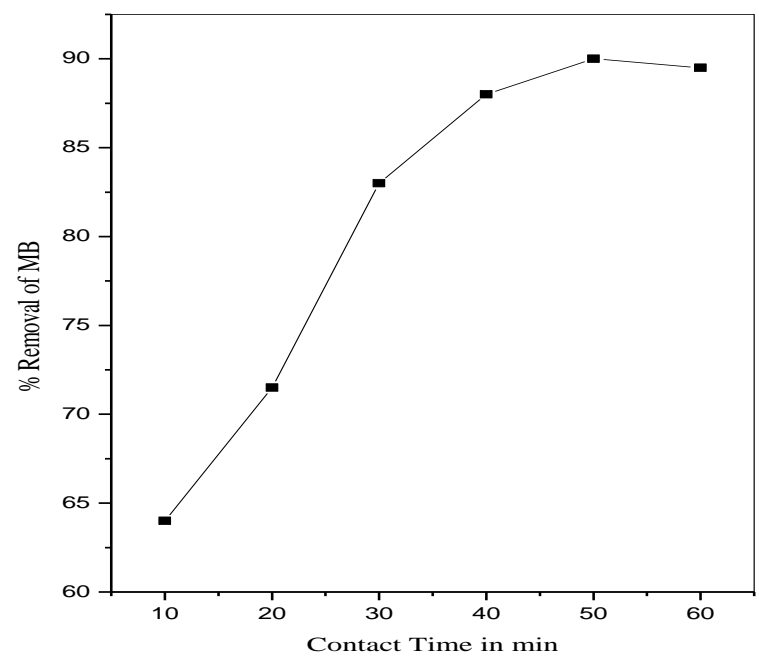

Fig: 1 - Effect of Contact Time on the Removal of MB Dye $[\mathrm{MB}]=50 \mathrm{mg} / \mathrm{L} ;$ Temprature $30^{\circ} \mathrm{C}$; Adsorbent dose $=25 \mathrm{mg} / 50 \mathrm{~m} 1$

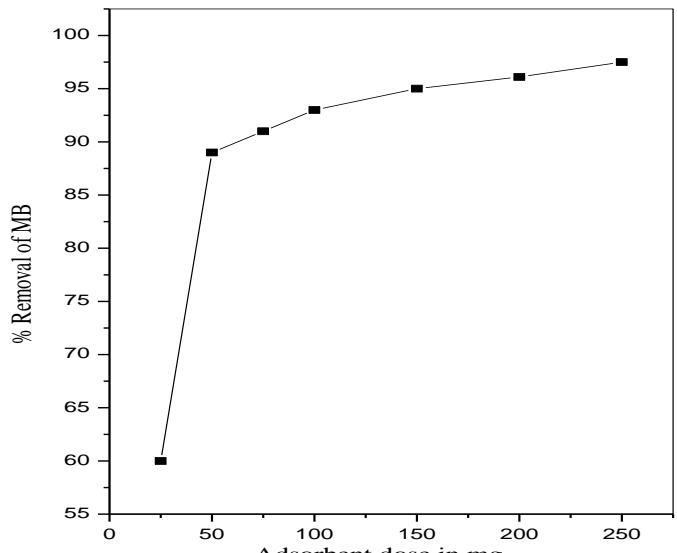

Fig;2- Effect of Adsorbent dose on the removal of MB Dye $[\mathrm{MB}]=50 \mathrm{mg} / \mathrm{L} ;$ Contact Time $50 \mathrm{~min} ;$ Temprature $30^{\circ} \mathrm{C}$

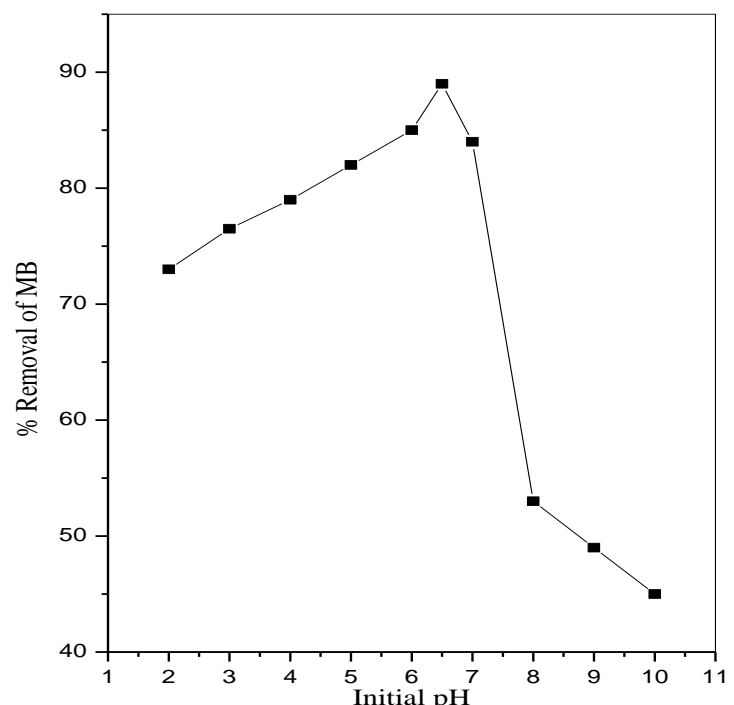

Fig;3- Effect of Initial pH on the removal of MB Dye $[\mathrm{MB}]=50 \mathrm{mg} / \mathrm{L} ;$ Temprature $30^{\circ} \mathrm{C}$;Adsorbent dose $=25 \mathrm{mg} / 50 \mathrm{ml}$ 